\title{
A presença de gatilho alimentar é asssociada a osmofobia em indivíduos com migrânea
}

\author{
Amanda Pasquini de Freitas, Ana Carolina Benetti Martini, Eloisa Cristine Lohse, \\ Maria Paula Bertoletti, Valéria Aparecida Bello (D), Regina Célial Poli Frederico (D), Aline Vitali da Silva
}

Pontifícia Universidade Católica do Paraná, Paraná, Brasil.

\author{
Introdução \\ A migrânea é caracterizada por episódios recorrentes de cefaleia que podem ser desencadeados por gatilhos \\ presentes na alimentação.
}

\section{Objetivo}

Identificar os preditores clínicos da presença de gatilho alimentar precedendo episódios de cefaleia em indivíduos com migrânea.

\begin{abstract}
Métodos
Estudo prospectivo do tipo caso-controle composto por pacientes com migrânea. A pesquisa foi aprovada pelo Comitê de Ética ( ${ }^{\circ}$ 3.029.972). Foi realizada entrevista estruturada e obtidos dados demográficos, clínicos, antropométricos e dados relacionados a migrânea e suas características. Os participantes responderam a questionários validados referentes a ao impacto da migrânea (HIT-6), depressão (IDB), ansiedade (STAIY2) e alodinia (ASC-12). Foi realizada análise univariada seguida de regressão logística binária e considerada diferença estatística quando p $\leq 0,05$.
\end{abstract}

\section{Resultados}

Participaram do estudo 409 indivíduos, 85,4\% eram mulheres, com mediana de 32 anos, 56,7\% tinham migrânea episódica e 37,4\% apresentavam aura. Dentre os participantes, 229 (55,9\%) relataram perceber gatilho alimentar precedendo episódios de cefaleia. Estes indivíduos apresentavam mais frequentemente sintomas de hipersensibilidade sensorial como fonofobia $(89,1 \%$ vs. $81,6 \%)$, fotofobia $(96,1 \%$ vs. $89,9 \%)$, osmofobia $(77,9 \%$ vs. $56,7 \%)$, alodinia $(56,9 \%$ vs. $42,9 \%)$ e aura $(43,7 \%$ vs. $29,4 \%)$, também apresentavam maior ansiedade $(4,8 \%$ vs. $1,2 \%)$ e impacto da migrânea $(89,5 \%$ vs. $79,6 \%)(p \leq 0,05)$. Em análise multivariada identificou-se que somente a osmofobia $(\mathrm{OR}=2,23 ; \mathrm{p}=0,009)$ e $\circ$ impacto da migrânea $(\mathrm{OR}=2,98 ; \mathrm{p}=0,007)$ permaneceram associados a presença de gatilho alimentar.

\section{Discussão}

Pacientes com osmofobia apresentaram 2,2 vezes maior chance de perceberem gatilho alimentar. Visto que não há ainda comprovação exata do motivo pelo qual alimentos desencadeiam cefaleia, aventa-se a hipótese de que a percepção sensorial causada pelo alimento e representada pela osmofobia seria um contribuinte da percepção de gatilho alimentar.

Palavras-chave: Migrânea, Gatilhos alimentares, Osmofobia, Ansiedade. 